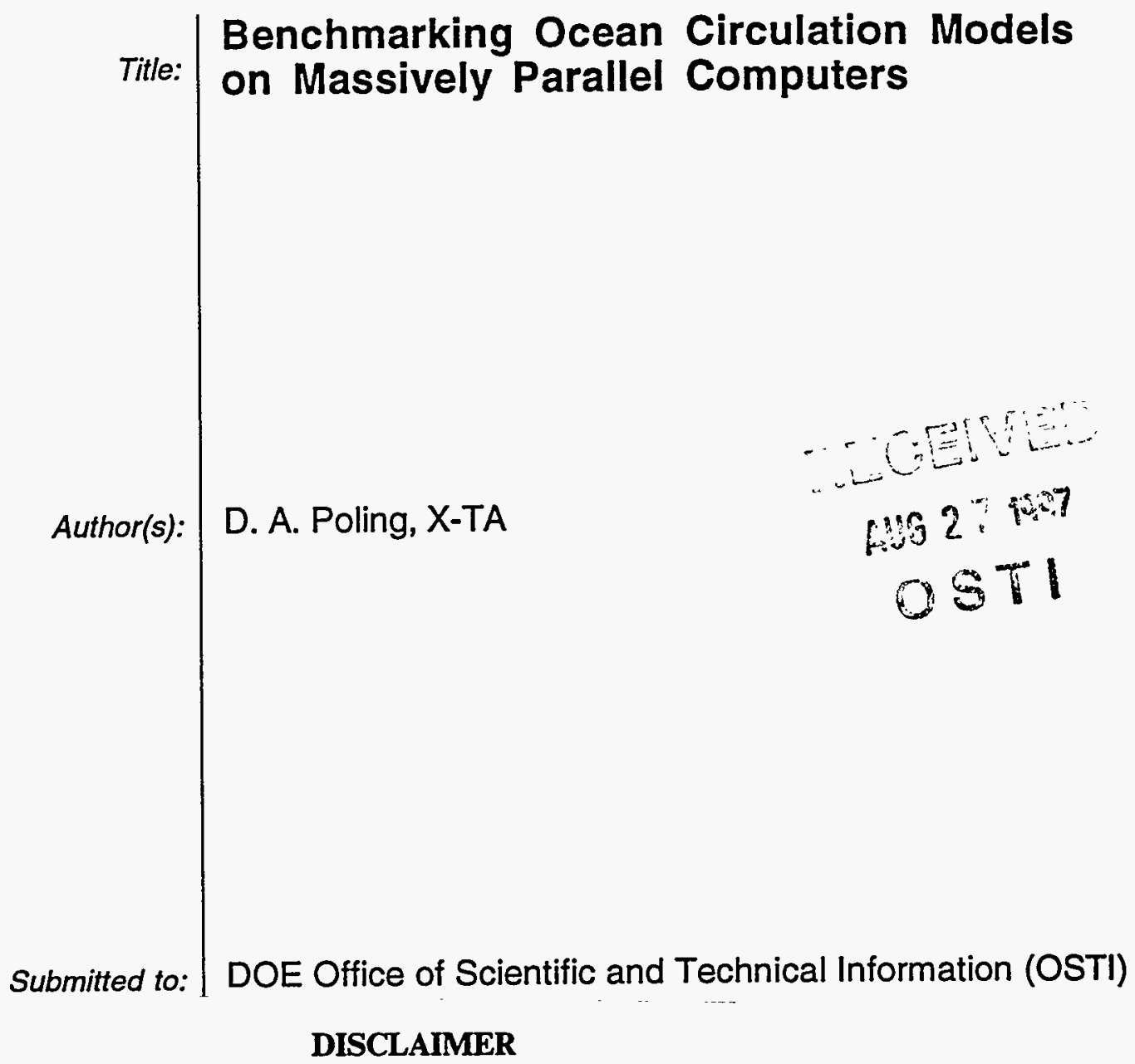

This report was prepared as an account of work sponsored by an agency of the United States Government. Neither the United States Government nor any agency thereof, nor any of their employees, makes any warranty, express or implied, or assumes any legal liability or responsibility for the accuracy, completeness, or usefulness of any information, apparatus, product, or process disclosed, or represents that its use would not infringe privately owned rights. Reference herein to any specific commercial product, process, or service by trade name, trademark, manufacturer, or otherwise does not necessarily constitute or imply its endorsement, recommendation, or favoring by the United States Government or any agency thereof. The views and opinions of authors expressed herein do not necessarily state or reflect those of the United States Government or any agency thereof.

Los Alamos Natlonal Laboratory, an affirmative action/equal opportunity employer, is operated by the University of Califomia for the U.S. Department of Energy under contract W-7405-ENG-36. By acceptance of this article, the publisher recognizes that the U.S. Government retains a nonexciusive, royaltyfreo linse to publish or reproduce the published form of this contribution, or to allow others to do so, for U.S. Government purposes. Los Alamos National free Icense to publish or reproduce the published form of this contribution, or under the auspices of the U.S. Department of Energy. Los Alamos National Laboratory strongly supports academic freedom and a researcher's right to publish; as an institution, however, the Laboratory does not endorse the vlewpoint of a publicalion or guarantee its technical correctress. 


\section{DISCLATMERR}

Portions of this document may be illegible in electronic image products. Images are produced from the best available original document. 


\title{
Benchmarking Ocean Circulation Models on Massively Parallel Computers
}

\author{
David A. Poling* \\ Applied Theoretical and Computational Physics Division
}

Los Alamos National Laboratory

\begin{abstract}
This is the final report of a three-year, Laboratory-Directed Research and Development (LDRD) project at the Los Alamos National Laboratory (LANL). The intention of this research was to establish the Laboratory in mainstream climate research in conjunction with the GEONET project.
\end{abstract}

\section{Background and Research Objectives}

General circulation models are becoming the premier theoretical tools for studying the complex structure of the global climate. GEONET was envisioned as exercising the resources developed for the nuclear weapons program to address environmental problems. The similarity of circulation models to weapons codes made them an attractive field for us to develop expertise. We hoped to become an active player in mainline climate research through computer simulation.

\section{Importance to LANL's Science and Technology Base and National R\&D Needs}

LANL has traditionally had not only one of the world's most powerful computing capabilities, but also access to the most advanced computing machines. It seemed clear if we were going to make contributions to climate research, this was a likely pathway.

*Principal Investigator, E-mail: dap@lanl.gov 


\section{Scientific Approach and Accomplishments}

Our approach was to investigate and experiment with various modelling codes while searching for a mainstream research partner who would temper our newness to the field with the substantial computing resources we brought to the problem. Our two major accomplishments were two sets of runs. The first was a landmark serial run of 100 simulation years on a high-resolution, coupled ocean/atmosphere model with no internal periodic forcing. The second was a set of 5 ensemble runs in which the same period of time was run several times with slightly different initializations. This could have a profound impact on understanding the inherent variability of such simulations.

Our initial objective was to develop a modelling component for the now defunct GEONET project. Most of the first year was spent doing background research on general circulation models and the various ways they are implemented and used. As a learning tool a box model was written to run on the CM 200 platform. A number of runs were also performed on the same platform with the POP ocean circulation model developed at LANL by Rick Smith and Bob Malone.

About this time Chick Keller, who was working to launch the GEONET project at Los Alamos, was talking to veteran climate modeller Tim Barnett at the Scripps Institute of Oceanography. Barnett had started an ambitious simulation project and Keller suggested that a good way to get connected to mainline climate research was by working with the researchers at Scripps.

The project was to do a long-term integration of a high-resolution, coupled ocean/atmosphere model. By long term we envisioned running for 100 simulation years. As it turned out we started running at year 25 and ran to year 125 . The atmospheric mesh was run at T42 resolution, which corresponds to about two and a half degrees. The ocean model roughly matched the resolution of the atmosphere and higher latitudes and was considerably finer near the equator. The oceans were truncated at 60 degrees in both northern and southern hemispheres and forced to Levitus data. This was the only forcing in the problem. Some parameters affecting mixing of ocean layers and of solar energy penetration of ocean water were adjusted to get realistic results, but there was no general forcing of either temperatures or salinities. This produced a model that ran stably for 100 years with very little climate drift.

Both the ocean and atmospheric codes were developed at Max Planck Institute for Meteorology. The atmospheric code is a spectral code. The differential equations that determine atmospheric circulation are decomposed into spherical harmonics and solved as systems of linear equations. This is an efficient solution scheme, but it does introduce 
some difficulties that I will refer to later. The ocean model is a primitive equation model in which the differential equations of motion are directly differenced and solved. The atmospheric model is named ECHAM and the principal author was Andreas Sterl at Max Planck. The ocean code is named HOPE and was written by Ernst Maier-Reimer at Max Planck and Joerg Wolff now at the University of Tasmania. Running in the coupled mode the code is referred to as ECHO.

An example of the potential difficulties with using spectral codes was discovered at the Geophysical Fluid Dynamics Laboratory in Princeton while we were doing this run. The U.S. Navy maintains a detailed database of global topography on a $1 / 2$ degree grid that is used by nearly all climate modelling groups. With a spectral code, however, the data goes into the code as Fourier-decomposed elements. As a result, when the topography is reconstructed, one sees Gibbs phenomena. The oceans are no longer flat and non-realistic ripples cross the oceans. Figure 1 shows a cross section along latitude 21 south. The model rings across the oceans. These false ocean ridges will induce anomalous precipitation over the oceans. Fixes for this problem are being researched, but they were not available as we did our runs.

It took several months to import all of the source codes, build the storage paths and write scripts to run the problems in batch mode. Once we had the model running reliably, there was still a lot of work to keep the problem moving along on the open Cray platforms. The full 100 year run required about 5000 hours of Cray CPU time, which is equivalent to over 200 days at 24 hours a day. It took more than a year and a half of diligent attention to get this run finished. An immense mountain of data was produced and stored on CFS. Literally hundreds of times the run was interrupted by some difficulty that required a detective job to find the problem, correct it, and find the proper files to restart the problem. During this time we were in constant communication with researchers at Scripps via $\mathrm{E}$-mail. This run has been quoted in the literature as being the state of the art for this kind of simulation.

The postprocessing on the data produced by this simulation literally will take years to finish. Researchers at Scripps and Los Alamos are currently working on this. While waiting on the postprocessing, a second series of runs was started. In these runs we ran the same ten-year period five times with slightly varying initial conditions. This is a powerful tool with which to examine the inherent variability of this type of simulation and that could have profound implications about the usefulness of such simulations for certain types of forecasting.

The PI of this LDRD project was invited by Dr. Wolff (one of the authors of the HOPE code) to come to the University of Tasmania and give a talk on the very 
preliminary results from the ensemble runs. During that talk, it was pointed out that for one variable, namely the 500 millibar height for one ensemble, the excursions after only 36 months seem uncorrelated and can even have opposite signed anomalies (see Fig. 2). This suggests that at least for some variables, climate models have a difficulty similar to the Lorenz problem with weather prediction. ${ }^{1}$

\section{Reference}

1. Lorenz, E. N., "Deterministic Nonperiodic Flow," Journal of Atmospheric Sciences, 357, 130-141 (1963). 


\section{Surface Elevation}

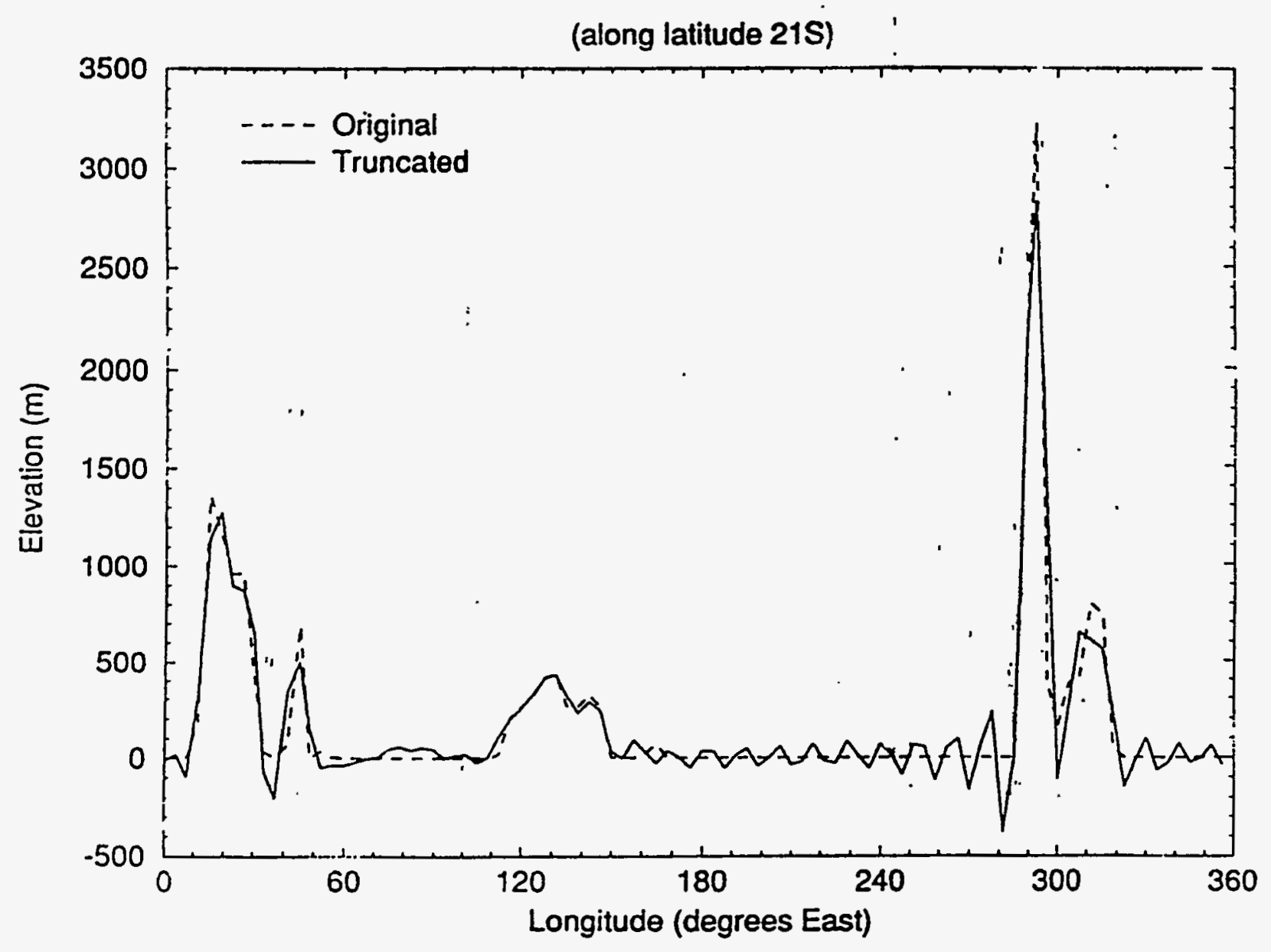

Figure 1. Surface elevation along latitude 21 south. Shown are the original U.S. Navy data and the surface as recreated from spectral representation as carried in the ECHAM code. 


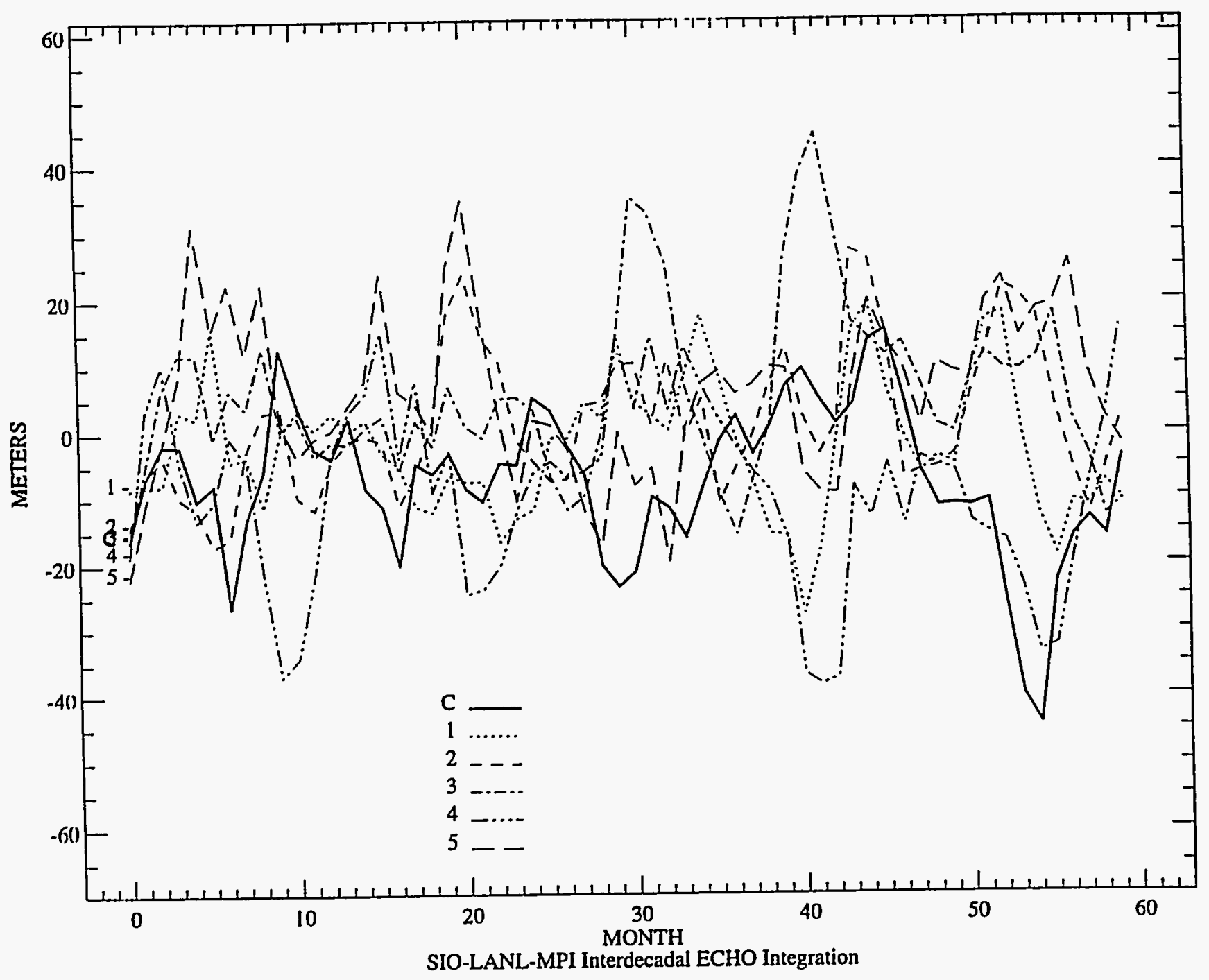

Figure 2. Anomalies of the 500 millibar height for a baseline run and five ensemble runs at one geographic locale. 